\title{
Analisis Prioritas Rehabilitasi Kerusakan Pada Daerah Aliran Sungai (DAS) Grompol Hilir Kabupaten Sragen, Jawa Tengah Dengan Metode Analytical Hierarchy Process (AHP)
}

\author{
Abdul Rohman Hadi $^{1)}$ Sugiyarto ${ }^{2)}$ Adi Yusuf Mutaqin ${ }^{3)}$ \\ 1)Mahasiswa Program Studi Teknik Sipil, Fakultas Tekik,Univerirtas Sebelas Maret, Email: \\ abdulrohman.hadi@gmail.com Jalan Ir. Sutami No.36A Surarata 57126
}

\begin{abstract}
The river is a natural waterway that flows into the oceans, lakes, seas or other rivers. River damage can cause a decline in the function of the river. River damage that occurs in tributaries in the Grompol downstream watershed causes river flow to overflow to residents in several locations. Efforts to restore river function in the form of maintenance and rehabilitation of rivers are needed to minimize the impact of disasters that may arise from such damage. With the limited budget that the government has for maintenance or rehabilitation, rehabilitation priorities are needed for rivers that need rehabilitation.

This study uses qualitative descriptive analysis. The object of the study in this research were tributaries in the Grompol downstream Watershed with six tributaries. Weighting and calculation of criteria assessment using the Analytical Hierarchy Process (AHP) method with a computer program Criterium Decision Plus Version 3.0. The primary datas used in the research are community participation in each research object, existing conditions of tributary, budget and cost plan of rehabilitation and service area.

Based on the results of the analysis of the Analytical Hierarchy Process (AHP) method and the level of damage in the tributaries is quite diverse from the collapse of the river wall to the presence of sedimentation. The results obtained using the Criterium Decision Plus (CDP) version 3.0 computer program shown the priority of rehabilitation in Kedungjeruk River with 17,9\%. the biggest contributions from the research we got that people participation is the biggest factor of rehabilitation priority process of the rivers in Grompol watershield.
\end{abstract}

Keywords: Demages, Rehabilitation, AHP

\begin{abstract}
Abstrak
Sungai merupakan jalan air alami yang mengalir menuju samudera,danau, laut atau ke sungai yang lain. Kerusakan sungai dapat menyebabkan menurunnya fungsi sungai tersebut. Kerusakan sungai yang terjadi di anak sungai pada daerah aliran sungai (DAS) Grompol Hilir menyebabkan meluapnya aliran sungai ke pemukiman warga di beberapa lokasi. Usaha untuk mengembalikan fungsi sungai berupa pemeliharaan serta rehabillitasi sungai perlu dilakukan untuk meminimalisir dampak bencana yang mungkin timbul dari kerusakan tersebut. Dengan keterbatasan anggaran yang dimiliki pemerintah untuk pemeliharaan atau rehabilitasi maka diperlukan prioritas rehabilitasi untuk sungai yang perlu dilakukan rehabilitasi.

Penelitian ini menggunakan analisis deskriptif kualitatif. Objek studi pada penelitian adalah anak-anak sungai yang berada pada Daerah Aliran Sungai (DAS) Grompol Hilir dengan enam anak sungai. Pembobotan serta perhitungan penilaian kriteria menggunakan metode Analytical Hierarchy Process (AHP) dengan program komputer Criterium Decision Plus Version 3.0. Data-data primer yang digunakan pada penelitian berupa partisipasi masyarakat yang berada di tiap-tiap objek penelitian, kondisi existing anak sungai, $\mathrm{RAB}$ rehabilitasi serta luas area layanan.

Berdasarkan hasil analisis metode Analytical Hierarchy Process (AHP) penilaian serta tingkat kerusakan yang ada pada anak-anak sungai cukup beragam dari runtuhan dinding sungai hingga adanya sedimentasi. Hasil yang didapat dengan menggunakan program komputer Criterium Decision Plus (CDP) version 3.0 menunjukkan prioritas rehabilitasi didahulukan pada Kali Kedungjeruk dengan 17,9\%. Kontribusi terbesar dari hasil penelitian ini didapat bahwa partisipasi masyarakat merupakan faktor terbesar dalam proses prioritas rehabilitasi pada anak-anak sungai di Daerah Aliran Sungai (DAS) Grompol Hilir.
\end{abstract}

Kata kunci: Kerusakan, Rehabilitasi, AHP 


\section{PENDAHULUAN}

Pada awal tahun 2018 diberitakan tentang masalah banjir di kabupaten Sragen yang dimuat dibeberapa media. Banjir merupakan salah satu permasalahan yang sering terjadi di suatu daerah terlebih saat musim penghujan datang. Banjir yang terjadi di Kabupaten Sragen tidak terlepas dari kondisi alam dan geografis itu sendiri. Selain itu,banjir yang terjadi di Kabupaten Sragen merupakan imbas dari luapan Sungai Bengawan Solo yang mengakibatkan peningkatan volume aliran pada Daerah Aliran Sungai (DAS) disekitar DAS Bengawan Solo.

Penelitian ini difokuskan kepada anak-anak sungai yang bermuara di sungai Grompol. Terdapat enam anak sungai sebagai fokus penelitian untuk mengetahui tingkat prioritas rehabilitasi pada tiap-tiap anak sungai. Anak sungai yang dimaksud tersebut diantarannya adalah sungai Bakung, sungai Klengkon, sungai Craken, sungai Gebang, sungai Wuluh, dan sungai Kedungjeruk. Keseluruhan sungai tersebut berada pada kecamatan Masaran wilayah administratif Kabupaten Sragen.

\section{Landasan Toeri}

\section{Sungai dan Konsep Pengelolaan Sungai Sebagai Komponen Drainase}

Definisi yang ada sekarang mengenai sungai ialah bahwa sungai diartikan sebagai sistem drainase dan sanitasi alamiah. Sungai dianggap tempat untuk mengalirkan kelebihan air, tempat mengalirkan limbah cair, dan tempat membuang limbah padat yang tidak terpakai.

Karena sungai dianggap sebagai sistem drainase yang mengutamakan kecepatan aliran air dari lokasi yang dikeringkan wajar jika pembangunan sungai berarti merubah morfologi dan bentuk dasar sungai sekaligus merombak ekosistem sungai, kemudian menjadikannya sebagai saluran drainse. Jelas cara pandang sungai seperti itu sangat destruktif terhadap sungai yang bersangkutan karena sungai tidak dipandang lagi sebagai suatu ekosistem tapi hanya dipandang sebagai suatu sistem drainase akhir.

Dirunut dari hulunya, bangunan sistem drainase terdiri dari saluran penerima (interceptr drain), saluran pengumpul (collector drain), saluran pembawa (conveyor drain), saluran induk (main drain), dan badan penerima (receiving water) dimana badan penerima itu sendiri adalah sungai-sungai yang merupakan bagian akhir drainase (Suripin, 2004).

\section{Kerusakan Sungai}

Kerusakan sungai merupakan salah satu penghambat jalannya aliran air sehingga mengurangi fungsi sungai secara normal. Kerusakan yang ada pada anak-anak sungai di DAS Grompol ini secara umum merupakan longsoran pada dinding sungai serta penumpukan sedimen pada beberapa tikungan sungai yang menyebabakan aliran air tersendat, untuk itu perlu adanya proteksi untuk mengembalikan fungsi sungai tersebut.

\section{Metode Analytical Hierarchy Process (AHP)}

Metode Analytical Hierarchy Process (AHP) merupaka teori umum mengenai pengukuran. Empat macam skala pengukuran yang biasanya digunakan secara berurutan adalah skala nominal,ordinal,intervsl dan rasio. Skala yang lebih tinggi dapat dikategorikan menjadi skala yang lebih rendah namun tidak sebaliknya.

\section{Penyusunan Hierarki}

Penyusunsan hierarki adalah penyusunan berbagai elemen dari suatu sistem yang kompleks secara hirarki agar dapat dipahami dalam pemecahan masalah. Hierarki merupakan alat dasar dari pikiran manusia dalam rangka menata suatu elemen ke dalam beberapa tingkatan. Hierarki dapat dibedakan menjadi dua yaitu struktur dan fungsional. Pada hierarki struktural sistem yang kompleks menjadi elemen-elemen pokoknya menurut hubungan esensialnya. Setiap set elemen dalam hierarki fungsional menduduki satu set hierarki dimana tingkat puncak disebut fokus atau tujuan dan hanya memuliki satu elemen dan merupakan sasaran keseluruhan atau tujuan diaplikasikannya model AHP dalam analisis.

\section{Pembobotan}

Pembobotan dilakukan dengan memberikan nilai dari angka yang terkecil hingga yang terbesar dengan interval pembobotan tertentu. Pembobotan dilakukan untuk semua kriteria, yakni partisipasi masyarakat, tingkat kerusakan sungai, luas area layanan, estimasi biaya rehabilitasi (Cahyo,dkk 2013). Prosedur AHP mengandalkan teknik pembobotan untuk menghasilkan faktor bobot. Faktor bobot ini menggambarkan ukuran relatif tentang pentingnya suatu elemen dibandingkan dengan elemen yang lainnya (Sumbangan 
Baja,2002).

\section{Penentuan Prioritas Alternatif}

Sumbangan Baja (2002) menjelaskan penentuan prioritas pilihan dalan AHP dilakukan dengan menghitung eigenvector dan eigenvalue melalui operasi matrik. Eigenvector menentukan ranking dari alternatif yang dipilih, sedangkan eigenvalue untuk memberikan ukuran konsistensi dari proses perbandingan. Ranking pada dasarnya diwakili oleh vector prioritas, sebagai hasil normalisasi eigenvector utama, ini akan didapat darin perhitungan vector kolom $(V j)$ dengan persamaan berikut:

$V j=K i j X W i$

Dimana Kij adalah matrik dengan bentuk sebagai berikut :

$$
\left(\begin{array}{ccccc}
\text { w11 } & w 12 & \ldots & \ldots & \text { w1p } \\
\text { w2 } 1 & w 22 & \ldots & \ldots & \text { w2p } \\
\ldots & \ldots & \ldots & \ldots & \ldots \\
\text { Wn } & w n 1 & \ldots & \ldots & \text { w } 2
\end{array}\right)
$$

Dengan tujuan obejective $\mathrm{i}=(1,2,3, \ldots \mathrm{p})$, dan wn adalah bobot alternatif 1 untuk tujuan 1 , p mewakili jumlah alternatif, dan $\mathrm{n}$ adalah jumlah tujuan. Vector kolom (Vj), menyatakan ranking akhir dari sekian alternatif yang diuji dalam analisis.

\section{Perhitungan Indeks Konsistensi (CI)}

Perhitungan ini dimaksudkan untuk mengetahui konsistensi jawaban yang akan berpengaruh pada kesahihan hasil (Rulan,2013). Pengukkuran konsistensi dari suatu matriks didasarkan atas suatu eigenvalue maksimum ( $\lambda$ maks). Makin dekat $\lambda$ maks dengan $n$, maka konsisten hasil yang dicapai. CI adalah ukuran simpangan atau deviasi yang dinyatakan sebagai berikut:

$\mathrm{CI}=\frac{(\lambda \text { maks }-\mathrm{n})}{(\mathrm{n}-1)}$

Dengan:

$\mathrm{CI}=$ Indeks Konsistensi

$\lambda$ maks $=$ eigenvalue maksimum

$\mathrm{n} \quad=$ banyaknya parameter yang digunakan

eigenvalue maksimum suatu matrik tidak akan lebih kecil dari nilai $\mathrm{n}$ sehingga tidak mungkin ada nilai CI yang negative.

Untuk mengetahui apakah CI dengan besaran tertentu cukup baik atau tidak perlu diketahui rasio yang cukup baik yaitu apabila CR $<0.1$

Dimana $C R=\frac{C I}{R I}$

Dengan :

$\mathrm{CR}=$ Rasio Konsistensi

$\mathrm{CI} \quad=$ Indeks Konsistensi

RI = Indeks Acak

\section{METODE PENELITIAN}

Penelitian ini menggunakan analisis deskriptif kualitatif yaitu metode penelitian yang digunakan untuk meneliti pada kondisi obyek alamiah, dimana peneliti adalah sebagai instrumen kunci, teknik pengumpulan data dilakukan secara triangulasi (gabungan), analisis data bersifat induktif, dan hasil penelitian kualitatif lebih menekankan makna dari pada generalisasi (Sugiyono,2016).

\section{Obyek Penelitian}

Obyek penelitian yang dimaksud adalah anak-anak sungai pada DAS Grompol Hilir di Kabupaten Sragen.

\section{Data Penelitian}

\section{Data Primer}

Data primer pada penelitian ini diperoleh dari responden melalui kuisioner serta survey kepada masyarakat yang berada di daerah obyek penelitian, data kerusakan sungai berupa endapan dan runtuhan dinding sungai, serta data luas area layanan yang didapat dari citra satelit secara terbatas. responden direncanakan berjumlah 15 orang yang dipilih secara acak untuk tiap-tiap lokasi penelitian. 


\section{Data Sekunder}

Data sekunder yaitu data yang didapat dari dari catatan,buku,laporan pemerintah,artikel sebagai teori dan lain sebagainya. Data yang diperoleh dari data sekunder ini tidak boleh diolah lagi. Sumber yang tidak langsung memberikan data pada pengumpul data.

\section{Pengolahan Data}

Dalam penelitian ini data primer dan data sekunder yang berhubungan dengan faktor-faktor yang berpengaruh dalam kinerja normalisasi sungai pada obyek penelitian diolah untuk mendapatkan skor dan pembobotan pada masing-masing sub sistem. Kemudian dilakukan pengolahan data dengan bantuan program komputer Criterium Decision Plus (CDP) V.3.0.

\section{HASIL DAN PEMBAHASAN}

Partisipasi Masyarakat Terhadap anak Sungai Pada DAS Grompol Hilir

Penilaian terhadap partisipasi masyarakat terhadap anak sungai yang ada pada DAS Grompol hilir.

Tabel 1. Rekapitulasi Hasil Penilaian Kuisioner Partisipasi Masyarakat

\begin{tabular}{|c|l|r|}
\hline No & \multicolumn{1}{|c|}{ Nama Sungai } & $\begin{array}{c}\text { Hasil } \\
\text { Kuisioner }\end{array}$ \\
\hline \hline 1 & Kali Bakung & 38,40 \\
\hline 2 & Kali Klengkon & 38,07 \\
\hline 3 & Kali Craken & 38,47 \\
\hline 4 & Kali gebang & 37,33 \\
\hline 5 & Kali Wuluh & 41,60 \\
\hline 6 & Kali Kedungjeruk & 39,20 \\
\hline
\end{tabular}

\section{Tingkat Kerusakan Anak Sungai Pada DAS Grompol}

Berdasarkan pengamatan kerusakan anak sungai ditinjau dari adanya longsoran atau runtuhan pada dinding sungai. Kondisi tersebut dapat mengurangi fungsi sungai.

Tabel 2. Rekapitulasi Tingkat Kerusakan Anak Sungai Pada DAS Grompol Hilir

\begin{tabular}{|l|l|r|r|r|r|}
\hline No & \multicolumn{1}{|c|}{ Nama Sungai } & \multicolumn{1}{c|}{$\begin{array}{c}\text { Sedimantasi } \\
(\mathrm{m} 3)\end{array}$} & $\begin{array}{c}\text { Palian Tanah } \\
\text { Pondasi } \\
\text { Pasangan }(\mathrm{m} 3)\end{array}$ & $\begin{array}{c}\text { Total } \\
(\mathrm{m} 3)\end{array}$ & $\begin{array}{c}\text { Persentase } \\
(\%)\end{array}$ \\
\hline \hline 1 & Kali Bakung & 32,00 & 90,00 & 122,00 & 3,17 \\
\hline 2 & Kali Klengkon & 32,00 & 60,00 & 92,00 & 3,45 \\
\hline 3 & Kali Craken & 48,00 & 90,00 & 138,00 & 5,11 \\
\hline 4 & Kali Gebang & 12,80 & 10,00 & 22,80 & 2,35 \\
\hline 5 & Kali Wuluh & 12,80 & 10,00 & 22,80 & 2,29 \\
\hline 6 & Kali Kedungjeruk & 48,00 & 90,00 & 138,00 & 5,00 \\
\hline
\end{tabular}


Luas Area Layanan

Data luas area layanan pada tiap-tiap sungai yang diteliti didapat dari pengamatan citra satelit google.

Tabe1 3. Luas Area Layanan Masing-Masing Sungai Pada DAS Grompol Hilir

\begin{tabular}{|c|l|c|}
\hline No & \multicolumn{1}{|c|}{ Nama Sungai } & Luas Area Layanan ( Ha ) \\
\hline \hline 1 & Kali Bakung & 27,25 \\
\hline 2 & Kali Klengkon & 6,96 \\
\hline 3 & Kali Craken & 34,15 \\
\hline 4 & Kali gebang & 8,8 \\
\hline 5 & Kali Wuluh & 9,15 \\
\hline 6 & Kali Gedung jeruk & 18,53 \\
\hline
\end{tabular}

\section{Estimasi Biaya Rehabilitasi}

Estimasi biaya diperlukan untuk membangun pasangan batu kali pada tebing-tebing atau tanggul yang longsor dan mengangkat tanah timbul di sekitar bangunan pasangan pengaman tanggul. Penulis memperhitungkan sesuai dengan harga material dan upah tenaga kerja yang berlaku di Kabupaten Sragen ditahun penelitian yaitu tahun 2019. Namun sebelumnya penulis memperhitungkan dulu jumlah volume yang akan dikerjakan.

Tabel 4. Rekapitulasi Estimasi Biaya Rehabilitasi Anak Sungai Pada DAS Grompol Hilir

\begin{tabular}{|c|l|c|}
\hline No & \multicolumn{1}{|c|}{ Nama Saluran } & RAB ( Rp ) \\
\hline \hline 1 & Kali Bakung & $136.339 .149,40$ \\
\hline 2 & Kali Klengkon & $134.224 .141,40$ \\
\hline 3 & Kali Craken & $56.075 .467,71$ \\
\hline 4 & Kali gebang & $40.800 .456,48$ \\
\hline 5 & Kali Wuluh & $40.800 .456,48$ \\
\hline 6 & Kali Kedungjeruk & $222.952 .074,33$ \\
\hline
\end{tabular}

\section{Analisis Dengan Criterium Decision Plus (CDP) V.3.0}

Pada program Criterium Decision Plus Version 3.0 dapat menyediakan total 7 level tingkatan dan maksimum 500 blok diantaranya blok kriteria dan blok alternatif. Pada peneltian yang dilakukan penulis saat ini memiliki 4 (empat) kriteria dan 6 (enam) alternatif. Ke empat kriteria tersebut diantaranya partisipasi masyarakat,tingkat kerusakan sungai,luas area layanan dan estimasi biaya biaya rehabilitasi. Sedangkan alternatif yang digunakan ada enam alternatif diantaranya yaitu Kali Bakung, Kali Klengkon, Kali Craken, Kali Gebang, Kali Wuluh, Kali Kedungjeruk. 


\section{Grafik Hasil Pengolahan AHP}

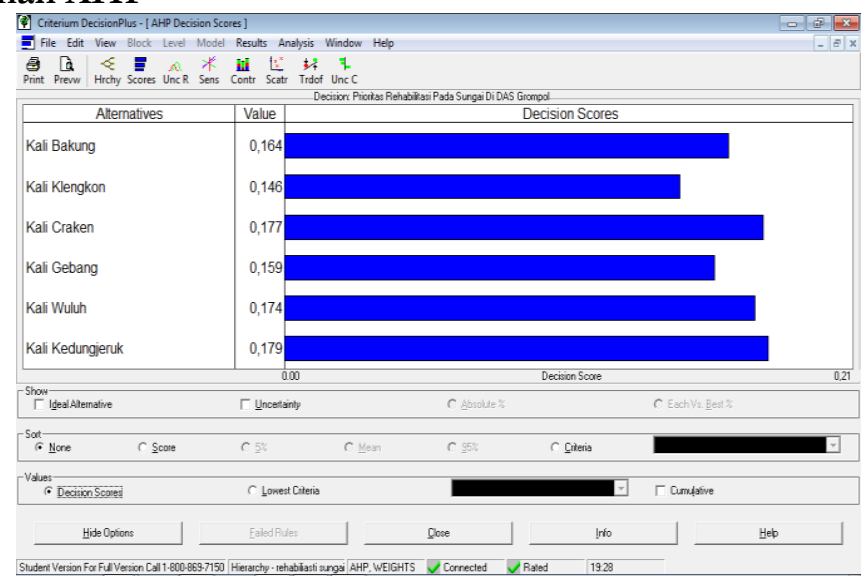

Gambar 1. Grafik Hasil Pengolahan Akhir AHP pada program komputer CDP V3.0

Gambar grafik diatas menunjukkan hasil akhir pengolahan pada metode AHP. Dari hasil tersebut dapat dilihat masing-masing persentase perolehan nilai yang nantinya akan menjadi prioritas dalam melakukan tindakan rehabilitasi. Dari data diatas Kali Kedungjeruk memiliki persentase terbesar yakni sebesar 17,9\% hal ini berarti bahwa Kali Kedungjeruk menjadi prioritas rehabilitasi , tingkatan kedua yaitu Kali Craken dan ketiga Kali Wuluh dengan persentase masing-masing memiliki persentase 17,7\% dan 17,4\%, prioritas selanjutnya ada pada Kali Bakung yang memiliki nilai persentase sebeasr 16,4 \% diikuti Kali Gebang dengan hasil persentase sebesar 15,9\%, hasil persentase sebesar 14,6\% adalah hasil persentase dari Kali Klengkon yang menjadi Kali dengan prioritas rehabilitasi terkahir.

\section{Grafik Kontrinbusi Rehabilitasi}

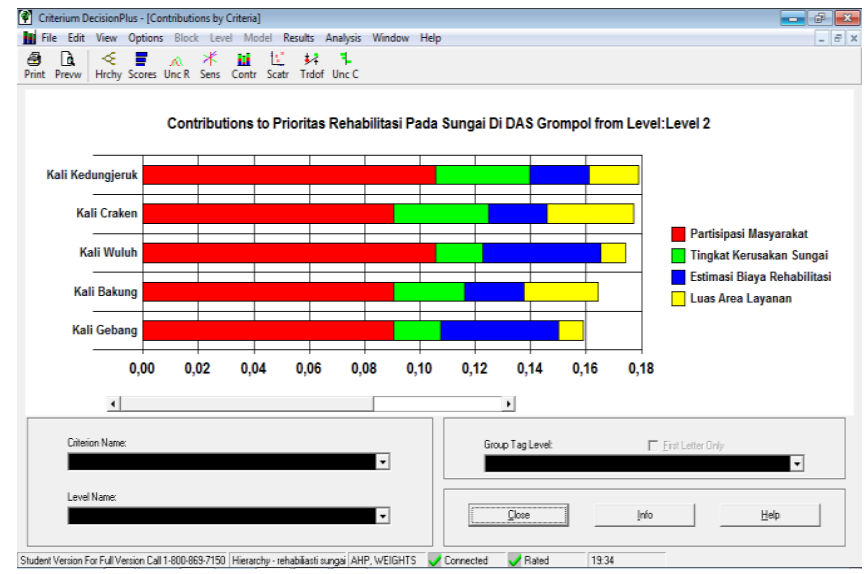

Gambar 2. Grafik Kontribusi Rehabilitasi Pada Sungai Di DAS Grompol

Grafik diatas menunjukkan kriteria paling dominan dalam kontribusi masyarakat pada rehabilitasi sungai pada DAS Grompol. Ditunjukkan bahwa kriteria partisipasi masyarakat memiliki kontribusi paling tinggi, hal ini menunjukkan bahwa partisipasi masyarakat menjadi kriteria paling dominan pada kasus ini.

\section{KESIMPULAN DAN SARAN}

\section{Kesimpulan}

Dari hasil penelitian yang telah penulis lakukan,maka dapat penulis tarik butir kesimpulan diantaranya:

Tingkat kerusakan yang ada pada anak sungai di DAS Grompol sangat beragam. Namun dari beberapa kerusakan yang diamati saat penelitian jenis kerusakan didominasi oleh runtuhan dinding sungai dan adanya sedimentasi.

Dari kriteria-kriteria yang ada pada proses penelitian seperti Partisipasi Masyarakat, Tingkat Kerusakan Sungai, Luas Area Layanan dan Estimasi Biaya Rehabilitasi. Partisipasi Masyarakat adalah faktor yang paling berpengaruh terhadap rehabilitasi anak sungai yang ada pada DAS Grompol.

Pada gambar 1 dapat diketahui bahwa prioritas persentase perolehan nilai pada masing-masing anak sungai untuk dilakukan tindakan rehabilitasi. Dari data dapat disebutkan bahwa Kali Kedungjeruk 
memiliki persentase terbesar untuk dilakukan tindakan rehabilitasi lebih dulu dengan hasil persentase sebesar $17,9 \%$.

\section{Saran}

Adapun saran-saran yang penulis sampaikan adalah sebagai berikut:

Pemerintah dalam hal ini Dinas Pekerjaan Umum dapat lebih memperhatikan kondisi sungai yang ada agar dapat mejalankan fungsinya secara normal.

Masyarakat,terutama masyarakat yang bermukim di dekat sungai terkait diharapkan mampu lebih berperan aktif dalam menjaga fungsi sungai.

Perlu adanya kajian lebih matang dan mendalam dapat berupa penelitian selain menggunakan metode AHP untuk mengetahui perbedaan hasil yang didapat.

\section{UCAPAN TERIMAKASIH}

Allah SWT yang telah memberikan banyak nikmat-Nya sehingga penelitian ini dapat terselesaikan, orang tua tercinta yang selalu memberikan dukungan tiada henti,Ir. Sugiyarto, MT dan Ir. Adi Yusuf M, MT yang telah banyak membimbing dan memberikan arahan dalam penulisan penelitian ini, serta temanteman sipil seperjuangan.

\section{REFERENSI}

Adi Yusuf Muttaqien,.2007. Kinerja Sistem Drainase Yang Berkelanjutan Berbasis Partisipasi Masyarakat (Studi Kasus di Perumahan Josroyo Indah Jaten, Kabupaten Karanganyar). Universitas Sebelas Maret Surakarta: Surakarta.

Agus Maryono, 2016, Reformasi Pengelolaan Sumber Daya Air, Gadjah Mada University Press: Yogyakarta.

Bayu Cahyo Sriutomo ; Adi Yusuf Muttaqien; Fajar Srihandayani. 2013, Rehabilitasi Saluran Drainase Kabupaten Karanganyar Pada Subsistem Songgorunggi,Jurnal, Universitas Sebelas Maret, Surakarta.

Chay Asdak, 1995, Hidrologi dan Pengelolaan Daerah Aliran Sungai, Gadjah Mada University Press: Yogyakarta.

Djirjize Abdul Hakim Fatkhurrohman. 2014, Analaisis Angkutan Sedimen Dasar Sungai Bengawan Solo Ruas Serenan-Jurug, Skripsi, Universitas Sebelas Maret, Surakarta.

Fery Suryanto. 2011, Analisis Faktor Yang Mempengarubi Kinerja dan Rehabilitasi Sistem Drainase Mikro DAS Jurug Bengawan Solo Dengan Pendekatan AHP, Skripsi, Universitas Sebelas Maret, Surakarta.

Habib Ismail. 2011, Prioritas Rehabilitasi Sistem Drainase Mikro Daerah Aliran Sungai (DAS)Ｋ KaliＰepe Hulu Kota Surakarta, Skripsi, Universitas Sebelas Maret, Surakarta.

R. Rulan Oktaharandi. 2013, Prioritas Pemeliharaan Jalan Non Lingkungan Di Kota Surakarta Dengan Metode AHP, Skripsi, Universitas Sebelas Maret, Surakarta

Ratnasari Kusumaningrum. 2014, Analisis Angkutan Sedimen Anak Sungai Bengawan Solo Pada Sungai Dengkeng, Skripsi, Universitas Sebelas Maret, Surakarta.

Robert Kodoatie. 2003, Manajemen dan Rekayasa Infrasturktur, Penerbit Pustaka Pelajar,Yogyakarta.

Robert J. Kodoatie, Roestam Sjarief. 2008, Pengelolaan Sumber Daya Air Terpadu, ANDI, Yogyakarta.

Saaty, T. L, 1993, Pengambilan Keputusan Bagi Para Pemimpin Untuk Pengambilan Keputusan Dalam Situasi Yang Komplekes, PT. Pustaka Binaman Pressindo: Jakarta.

Saaty, Thomas L. Vargas, Luis G. 2012. Models, Methods, Concept \& Applications of The Analytical Hierarchy Process-Second Edition. Springer Science+Business Media: New York.

Suripin. 2004. Sistem Drainase Perkotaan Yang Berkelanjutan.. Andi: Yogyakarta.

V. Wiratna Sujarweni. 2014, Metodologi Penelelitan, Pustaka Baru Press: Yogyakarta. 